\title{
Managing Marine Mammals and Fisheries: A Calibrated Programming Model for the Seal-Fishery Interaction in Sweden
}

\author{
Torbjörn Jansson $^{1} \cdot$ Staffan Waldo ${ }^{1}$ (D)
}

Accepted: 25 November 2021 / Published online: 27 December 2021

(c) The Author(s) 2021

\begin{abstract}
This paper develops a model based on the concept of Positive Mathematical Programming (PMP) that is useful for ex-ante analyses of how policy measures affect commercial fisheries. PMP models are frequently used in agriculture, but rarely for analyzing fisheries. Fisheries often face a large set of constraints such as effort regulations and catch quotas of which some might be binding and others not. An econometric approach is developed for calibrating models with both binding and non-binding constraints. The interaction between seals and Swedish fisheries is used as an empirical application. Seal interaction is modeled as seals predating fish from passive gear (nets and hooks), which is primarily an issue for the coastal fishery. The model contains 24 fleet segments involved in 247 different fishing activities in 2012. The results show that if no further management action is taken, fisheries using passive gear will reduce their activities from about 46000 days at sea per year to about 41000 and reducing their economic performance from losses of about 2 million Euros to about 3.3 million. The impact from seals can be reduced by reducing the seal population or providing economic compensation.
\end{abstract}

Keywords Fisheries · Marine mammals · Positive mathematical programming

\section{Introduction}

A striking feature of fisheries management is the strong and often immediate interaction between fisheries policies and economic consequences. To meet the need for ex-ante information on the economic impact of fisheries management, policy-oriented bio-economic fisheries models have been developed. Such models integrate both biological and economic features in order to evaluate the impact of fisheries policies. Prellezo et al. (2012) and Nielsen et al. (2018) provide overviews of integrated ecological-economic fisheries

Torbjörn Jansson

torbjorn.jansson@slu.se

Staffan Waldo

staffan.waldo@slu.se

1 Department of Economics, AgriFood Economics Centre, Swedish University of Agricultural Sciences, PO Box 7080, 22007 Lund, Sweden 
models (IEEFM) used for policy analyses. The overviews show a need for multiple models with different modeling features, such as multiple or single species, optimization or simulation models, static or dynamic models, etc. We develop a new model of the Swedish commercial fisheries based on concepts from agricultural models using Positive Mathematical Programming (PMP) and apply it to analyze the interaction between seals and fisheries.

The agricultural economic literature frequently discusses issues of model calibration, i.e. how constrained optimization models can be brought to replicate empirical observations. The dominating methodological framework is Positive Mathematical Programming (PMP), which aims to calibrate constrained mathematical programming models to observed behavior. The seminal paper by Howitt (1995) presented a calibration method that was technically easy to implement in existing models and therefore was quickly adopted by many modellers. That method was followed by variations that overcome certain limitations of the initial method ${ }^{1}$ (e.g. Röhm and Dabbert 2003), theoretical work on the properties of such calibrations such as the range of supply elasticities that can be reproduced (Mérel and Bucaram 2010) and attempts to apply econometric techniques such as Maximum Entropy (Heckelei and Wolff 2003) or Bayesian methods (Jansson and Heckelei 2011) to further strengthen the empirical content of such models. Models based on PMP are regularly used in applied analyses (c.f. the review by Heckelei et al. 2012) where they provide insights on how agricultural policies affect the sector. Fisheries models are almost absent from the literature on PMP and the review of fisheries models by Nielsen et al. (2018) does not mention calibration nor other methods to align model balselines with empirical data. An exception is the paper by Sweeney et al. (2017), who apply a PMP model for Hawaii's longline fishery.

The calibration problem in PMP models becomes more complex the more inequality constraints there are in the model because the economic value of the constraint, which is a dual variable of the model, is typically not observed and must be set in concordance with variables such as catch and effort (days at sea). Fisheries policies are often rife with inequalities in the form of catch quotas and effort restrictions. Methodologically, our study contributes (i) to the literature on PMP by extending an econometrically based calibration method to the case with many potentially non-binding restrictions, and (ii) to the fisheries literature by showing how techniques adapted from agricultural economics can be used to align model baselines with empirical data.

The seal-fisheries interaction in Sweden used for the empirical application is a special case of a more general issue of interactions between fisheries and marine mammals. Due to successful conservation measures, many marine mammal populations are currently recovering at a global level (Magera et al. 2013) which will increase future interactions between mammals and fisheries. ${ }^{2}$ This includes e.g. bycatch of marine mammals (Read, Drinker, and Northridge 2006; Read 2008; Lent and Squires 2017), fish stock recovery (Cook and Trijoulet 2016; Costalago et al. 2019), and competition for resources (Hansson, et al.

\footnotetext{
1 Three such shortcomings were: (i) to give a reasonable behaviour to more than $n-m$ activities of the $n$ activities in a model with $m$ constraints. For technical reasons, the original method gave different secondorder properties for one activity per resource constraint in the model. (ii) to parameterize technical variants or alternative activities that could be used but not observed in the data set. (iii) to calibrate also the dual values of the constrained resources in a way that is consistent with the primal simulation model and the data.

2 E.g., Wickens (1995) finds that 36 of 45 pinniped species analyzed interacted with either fisheries or fish farms.
} 
2017; Reidy 2019; Goldsworthy et al. 2019). ${ }^{3}$ The economic consequences of interactions between commercial fisheries and marine mammals have previously been studied by e.g. Flaaten and Stollery (1996) who estimated that a $10 \%$ increase in the northeast Atlantic minke whale (Balaenoptera Acutorostrata) population reduce the gross profit of the Norwegian cod and herring fisheries by between 2.8 and 6.7\%. Holma et al. (2014) found the net present value of profits in the Finnish salmon fishery to be approximately double in scenarios without seals, while Finnoff and Tschirhart (2003) estimate that the commercial harvest of prey species (pollock) had a significant role to play in the decline of the endangered Stellar sea lion in the northern Pacific.

The model developed in this paper is a short-term PMP model with detailed information on the fishery, but without dynamic components for investments/disinvestments in the fleet and the development of fish stocks or seal populations over time. It contains a high degree of details (24 fleet segments taking part in 247 fisheries and landing 44 different species) and provides result indicators (e.g. days at sea, economic indicators, landings, etc.) for each of these. This is important since many stakeholders will base their responses on how their specific fleet is affected in the short run and not the long-run effects when the ecosystem and fleets have had time to adjust to an equilibrium.

The paper is outlined as follows. In Sect. 3 we provide the specific setting of Swedish fisheries and seal management, which is necessary before turning to the empirical model. Section 4.2 contains the model and Sect. 5.3 the calibration approach. In Sect. 6 the data and calibration results are presented. Section 7.4 contains the seal management scenarios analyzed in the empirical application, and Sect. 7 the empirical results. The results are discussed in Sect. 8 and the empirical findings are summarized in Sect. 8.1.

\section{Swedish Seal and Fisheries Management}

The majority of interactions between Swedish fisheries and marine mammals are with the grey seal (Halichoerus grypus). This is a common species in the North Atlantic along both the European and American coastlines, where they interact with fisheries in a similar way as in Sweden (Wood et al. 2011; Cronin et al. 2014). The interactions with seals take three forms: competition for the resource, seals predating on catch from fishing gear, and parasite infections affecting the quality of the fish. In this paper, the economic effects of seals predating from fishing gear is analyzed. This causes catch to decline and costs to increase due to broken gear and working time spent on seal interactions. This is the economically most important direct interaction between fisheries and seals (Swedish Agency for Marine and Water Management, SwAM 2019; Swedish EPA 2020). Major efforts have been made to find seal-proof gear that is also efficient for catching the target species but such gear is still in the developing phase and not commercially available (Königson et al. 2015) with the exception of salmon traps (Hemmingsson, Fjälling, and Lunneryd 2008). Seals predating from fishing gear is primarily a problem for fisheries using gill-nets and hooks (Königson et al. 2007; Königson et al. 2009) thus affecting the coastal fishery. The coastal fishery is small in economic terms (Waldo and Blomquist 2020) but is viewed as important to maintain by both Swedish (SwAM and Swedish Board of Agriculture 2021) and European

\footnotetext{
3 These interactions are analogous to issues faced in terrestrial ecosystems where mammals interact with agriculture and other human activities (Shackelford et al., 2015).
} 
(European Union 2013) fisheries management. The Baltic Sea grey seal population was at a critically low level (about 4000 individuals) in the 1970's due to toxic substances ${ }^{4}$ in the ecosystem (SwAM 2019) but has increased rapidly since then; in 2013 the total population was estimated to be about 43,000 (Hansson et al. 2017, Supplement 1). The carrying capacity for seals in the Baltic Sea is not scientifically defined, but Harding and Härkönen (1999) estimate that in the beginning of the twentieth century the population of grey seals was about 88,000-100,000 individuals. Two more seal species interact with Swedish fisheries, although to a considerably smaller extent than the grey seal; The ringed seal (Phoca hispida) with about 10000 individuals in the Baltic Sea and the harbor seal (Phoca vitulina) with about 15000 individuals primarily in the Kattegat and Skagerrak (SwAM 2014).

All seal species in Swedish waters are listed in the EU Habitats Directive (European Union, 1992) as species of community interest. The directive states that these species should be managed to obtain a favorable conservation status, implying the following: (1) the population shall be viable, (2) the natural range of the species should not be reduced or be likely to be reduced in the future, and (3) there will continue to be a sufficiently large habitat to maintain the population. In the national implementation of the Habitats Directive, Sweden works with a floor of 10,000 individuals for the grey seal population to be viable, which is based on regional recommendations by the Helsinki Commission (Helcom 2018). In the terminology of the EU Marine Strategy Framework Directive (European Union 2008a), this is an indicator of so-called Good Environmental Status (GES, used in the scenario definitions below) for seals. However, in the Swedish management plan for grey seals (SwAM 2019) societal values are defined more broadly than mere seal population status. It is explicitly stated that the net aggregate impact on human interests shall be neutral or positive. The current regulation allows hunting to remove individual seals specializing in eating from fishing gear (protective hunting), and hunting for reducing population levels (licensed hunting). A motivation for licensed hunting is to lower the interaction with fishing gear in general (Swedish EPA, 2020). However, the number of individuals allowed to remove is small (2000 seals 2020) which implies that the seal population is expected to grow towards carrying capacity, although at a slower growth rate than without hunting (note that no large-scale hunting is allowed in other Baltic Sea counties either). Swedish fishers are eligible for economic compensation for damage caused by seals. About 1.5 million euros of national funds (i.e., not EU funds) are distributed annually based on reported interactions between seals and fishing gear.

The Swedish fishing industry is diverse and contains fleet segments ranging from largescale pelagic trawlers to small coastal vessels. Furthermore, the fishing grounds cover both the North Sea (primarily the Kattegat and Skagerrak) and the Baltic Sea, and both marine and estuarine areas. Major species are herring (Clupea harengus), sprat (Sprattus sprattus), mackerel (Scomber scombrus), cod (Gadus morhua), Norway lobster (Nephrops norvegicus), and northern shrimp (Pandalus borealis), but many small-scale fisheries are also dependent on freshwater species such as vendace (Coregonus albula), pike (Esox lucius), and perch (Perca fluviatilis), which are common in the Baltic Sea (Bergenius et al. 2018). Regulations in the studied period (2012) consisted of a combination of catch restrictions and effort restrictions. An effort restriction is a limit on the fishing activities and is defined as a combination of fishing time and engine power of the vessel: so-called "effort days."

\footnotetext{
${ }^{4}$ PCB and DDT was found to accumulate in adipose tissue and disturb immune system functions and fertility. Concentrations of those pollutants have gradually decreased in the Baltic Sea since their use has been prohibited or strongly reduced.
} 
One day of fishing with a vessel with a $100 \mathrm{kWh}$ engine is equivalent to two days with a vessel with a $50 \mathrm{kWh}$ engine. This regulation was implemented in the North Sea for gear catching cod (EU, 2008b). Each member country had a limit on effort days for different fisheries. A typical case would be a limit on total national effort for Swedish vessels fishing for Norwegian lobster with non-selective trawls. In addition to the effort restrictions, total Swedish catches are not allowed to exceed the national quotas. The quotas are negotiated in the EU based on biological advice from the International Council for the Exploration of the Sea (ICES), and set on a yearly basis for each stock and country. Freshwater species caught in the Baltic Sea are not under quota regulations.

\section{The Model}

We develop a model that is static and short run, i.e. it has a fixed fleet of vessels and fixed stocks of fish. The model is a constrained optimization problem based on the notion of a fishery $(f)$, which is a combination of a vessel from a fleet segment (a segment contains vessels of a specific type and size) with a particular gear in a particular geographical area. Each fishery has a fixed distribution of catch of available species $s$ based on historical catches. An illustrative example of a fishery will be vessels that are 18-24 m long, bottom trawling in the Skagerrak, catching a mix of Norway lobster and cod. The same vessels can also be used for other fisheries, such as trawling for shrimp in the Skagerrak or cod in the Baltic Sea. Fishers are assumed to choose fishing effort $x_{f}$ for each fishery $f$ so as to maximize their profit, including subsidies (equation 1), limited by the existing fleet capacity and by catch quotas, season, and effort regulations. Vessels from a segment are limited to only use gear and areas that were observed for that segment in the data. In pracise this implies that e.g. vessels built for passive gear cannot be used for trawling, even if trawling is more economically efficient.

Revenues from fishing stem from landed catch for each fishery and species $s\left(L_{f s}\right)$ multiplied by the price $p_{f s}$. The price for the same species might differ depending on the gear and area used in the fishery. The marginal costs of fishing activities are assumed to increase when fishing efforts increase, so that each additional day at sea is marginally more expensive than the previous one. ${ }^{5}$ Therefore, variable costs are included in the objective function (equation 1) as a non-linear function with two parameters: one defining a constant cost per fishing day ( $v c a)$ and one defining how variable costs per day increase $(v c b)$. The objective function also contains a constant per-day calibration term $P M P_{f}$ per fishery that ensures that the observed fishing pattern is replicated by the model. Fixed costs $\left(f_{c}\right)$ per vessel are included in order to render the accounting complete, but they have no impact on behavior, since the number of vessels per segment is fixed. The objective function is mathematically expressed as

$$
\begin{gathered}
\max \sum_{f, s} p_{f s} L_{f s}+\sum_{f} s u b s_{f} x_{f}-\sum_{f}\left(v c a_{f} x_{f}+\frac{1}{2} v c b_{f} x_{f}^{2}\right) \\
-\sum_{s e g} f_{\text {seg }} \text { vessels } s_{\text {seg }}-\sum_{f} P M P_{f} x_{f}
\end{gathered}
$$

where $x_{f}$ is the fishing effort in days per fishery $f, p_{f s}$ is the price for fish for each fishery $f$ and species $s, L_{f s}$ is the landed catch for each fishery $f$ and species $s, s u b s_{f}$ is the subsidy

5 E.g. the operation radius increases, or less-accessible fishing sites have to be used. 
per day to fishery $f, v c a_{f}$ is the constant part of the marginal variable cost, $v c b_{f}$ is the slope parameter of the marginal variable cost function, vessels seg $_{\text {is }}$ is the number of vessels operating in each segment seg, $f c_{\text {seg }}$ is the fixed cost per vessel in each segment (impacting only profits), and $P M P_{f}$ is the term for calibration of constant cost (or revenue, if negative).

All catch has to be landed. The marginal catch is assumed to decline with increasing fishing effort following a Cobb-Douglas production function (c.f., Frost et al. 2013), as shown in Eq. (2). Decreasing marginal catch at a constant fish stock level occurs if the fisher chooses the best fishing spots and timings first.

$$
L_{f s}=\delta_{f s} x_{f}^{\beta_{f}} \#
$$

The (constant) fish stock factor is included in $\delta_{f s}{ }^{6}$ Thus, $\delta_{f s}$ both represents the size of the catch per additional effort and its distribution across species. Therefore, $\delta_{f s}$ bears some relation to Catch Per Unit of Effort (CPUE) often used in the literature, but it is not fully equivalent, since our marginal catch is not constant over fishing effort.

Quotas are defined for sets of fishing areas, here called Quota Area ( $q a)$, and for sets of species called Quota Species ( $q s)$. Quotas are modelled by Eq. (3), where $Q$ is the Swedish quota. The construction with the indicator set $\left(I_{q s, q a, f, s}\right)$ appears in several places, and hence we will explain it in detail at this first instance. The subscript $f, s: I_{q s, q a, f, s}$ reads as " $f$ and $s$ such that they belong to $q s$ and $q a$ ": i.e., for each quota species and quota area, the equation sums up the total landed catch of the relevant species $s$ caught by the relevant fisheries $f(s)$ belongs to quota species $q s$ AND fishery $f$ is active in quota area $q(a)$. All quota areas and quota species match the species and quotas regulated in the CFP.

$$
\sum_{f, s: I_{q s, q a f, s}} L_{f s} \leq Q_{q s, q a} \#
$$

Effort restrictions come in three types. For each segment, there is a maximum number of annual fishing days available (maxEffSeg), based on the number of vessels (4). Thus, if each vessel can operate for 250 days per year and there are ten vessels in a segment, total fishing effort for that segment is restricted to 2500 days. For each fishery, there is also a maximum number of days of fishing possible (maxEffFishery), based on factors such as season length and number of vessels participating in the fishery (5). Thus, the total effort in a fishery cannot exceed the number of vessels multiplied by the maximum days they can fish in that particular fishery. ${ }^{7}$ Similar to the previous equation, the notation $f: I_{\text {seg. }}$ in the sum means "fisheries $f$ that belong with segment seg."

$$
\begin{gathered}
\sum_{f: I_{\text {seg. } f}} x_{f} \leq \text { vessels }_{\text {seg }} \text { maxEffSeg }_{\text {seg }} \# \\
x_{f} \leq \sum_{\text {seg }: I_{\text {seg.f }}} \text { vessels }_{\text {seg }} \text { maxEffFishery }
\end{gathered}
$$

In the effort regulation, there are various rules that apply to groups of fishing activities (sets of fisheries in our model) and sets of fishing areas. This is implemented in (6), where

\footnotetext{
${ }^{6}$ A Cobb-Douglas function with variable fish stocks would be $\$ \$\left\{L_{-}\{\mathrm{fs}\}=\{\backslash \text { alpha }\}_{-}\{\mathrm{fs}\}\left\{\{\mathrm{x}\}_{-}\{\mathrm{s}\}^{\wedge}\{\{\backslash\right.\right.$ beta $\left.\left.\}_{-}\{\mathrm{s}\}\right\} \mathrm{x}\right\}_{-}\{\mathrm{f}\}^{\wedge}\left\{\{\text { |beta }\}_{-}\{\mathrm{f}\}\right\} \$ \$$, where $x_{s}$ is the fish stock for species $\mathrm{s}$ and $\beta_{s}$ is the coefficient for the fish stock. However, with constant stock size, $x_{s}$ is left out of the equation.

7 Note that a fishery might have a short season or being closed part of the year due to regulations such as fishing moratoriums during spawning.
} 
$k w_{f}$ is the installed engine class in kilowatts, $I_{e g, e a, f}$ is the indicator set defining $(=1)$ if fishery $f$ belongs to effort group $e g$ and is active in effort area ea, and maxEffortPerGroup is the upper bound defined in EU effort regulations.

$$
\sum_{f: I_{\text {eg,eaf }}} x_{f} k w_{f} \leq \text { maxEffortPerGroup }_{\text {eg,ea }} \#
$$

As mentioned in the introduction, seal interactions cause catches to fall and costs to increase. This is implemented in the model as follows. A decrease (increase) in seal abundance is implemented in the model as a proportional increase (decrease) in landed catch for fishing days with seal interaction modelled by the catchability parameter $\delta_{f s}$ in the Cobb-Douglas catch function.

$$
\delta_{f_{s}}=\delta_{f_{s}}^{\text {cal }}\left(1+\text { SealDAS } S_{f} * \text { Loss } *(- \text { PopChange })\right) \#
$$

In Eq. (7), $\delta^{\text {cal }}$ is the original (calibrated) catch coefficient, SealDAS $S_{f}$ is the share of DAS with seal interaction for each fishery, Loss is the share of fish eaten from the gear on days with seal interaction and PopChange is the change in the seal population. As an illustrative example, seals might affect $10 \%$ of fishing days $($ SealDAS $=0.1)$ and eat $50 \%$ of the total catch for those days (Loss $=0.5)$. If the seal population decreases by $50 \%$ $($ PopChange $=-0.5)$, then landed catch increases by $0.1 * 0.5^{*}(-(-0.5))=2.5 \%$. This procedure might cause negative catches in rare cases, but in such cases catches are set to zero. Remember that we only model seal interaction through seals predating from gear. Thus, the reduction in catch are not due to seals competing for the resource or fish with seal parasite infections.

The cost due to seals (e.g. broken gear) is assumed to change in proportion to the seal population. The cost of seal interactions per fishery in the baseline situation was adopted from Waldo et al. (2020a, b) who conducted a survey to Swedish fishers and calculated seal costs for relevant fisheries. A decrease in the seal population is assumed to decrease this cost proportionally, and this is implemented as a decrease of the constant part $\left(v c a_{f}\right)$ of the variable costs in (1). As an example, assume the constant part of the cost of a fishery is 1000 euros, and we know that 100 euros of this is due to seals. If the seal population decreases by $50 \%, v c a_{f}$ will be reduced by 50 euros and thus correspond to 950 euros.

In the model the seals' impacts on both revenues and costs are assumed to be proportional to the population size. Little is known from the literature on this topic, but fishers' express that the increase in seal abundance makes it difficult to avoid them (Johansson and Waldo, 2020) which indicates that more seals implies more interaction.

\section{Model Calibration}

Since we assume that the observed data represent a model equilibrium, we want the model to reproduce the 2012 data on fishing effort for each fishery $x_{f}$ when maximizing the objective function under the constraints (Eqs. 1-6). This requires calibration, i.e. we adjust model parameters to make it reproduce those observations "as good as possible". 


\subsection{Challenges to Calibration}

Many IEEFM models have an optimization routine that maximizes profit or minimizes cost (Nielsen et al. 2018). This could be viewed as a normative approach, giving advice on the optimal allocation of effort, given production constraints in the form of available quotas, gear restrictions, etc. The optimal allocation of effort might differ substantially from observed effort. In contrast, we build a positive model aiming to reproduce the observed fishing, and this is one of two key objectives of the calibration.

The other objective of the calibration relates to how the model reacts to changes. Even if the model reproduces observed effort for each fishery, the reaction to a small change in parameters might be unrealistic: either no change or a large jump may result, in particular if the model is linear. In a linear model, marginal profits of any individual fishery do not change if the fishing effort changes. Therefore, the optimal solution essentially first increases the most profitable fishery ${ }^{8}$ until some resource constraint binds, then increases the second most profitable activity, and so on, until all resource constraints are exhausted. Less profitable fisheries will not take place at all. If the profitability of an activity is reduced e.g. due to changed policies, the activity level will stay at its bound if it is still more profitable than other activities, or if not it will be strongly reduced. This phenomenon is referred to as overspecialization. Some models, such as FISHRENT (Salz et al. 2011, p. 57) apply flexibility constraints to keep the rate of change within pre-established bounds. Other models, such as the agricultural sector model described in Jonasson and Apland (1997), introduce a larger number of activities with alternative technologies that have slightly different rates of returns. That approach makes the model respond in finer increments to external shocks, but does not fundamentally solve the overspecialization problem for a given activity. Calibration can adjust the way the model reacts without using additional constraints or activities.

Before describing our approach to model calibration, we provide a brief review of the calibration problem and approaches to its solution. Central to all calibration approaches is that they adjust marginal costs and/or revenues so that at some pre-defined activity level, the marginal profitability ${ }^{9}$ of all activities is equal. In order for this point to be optimal compared to small changes, the calibration methods also make marginal profits of each activity decrease when the activity increases, typically by introducing increasing marginal costs or decreasing marginal yields. If such a calibrated activity would increase beyond the calibration point, its marginal profitability would become less than that of activities competing for the same resources, and hence the increase could no longer be optimal, and similar for a decrease. The slope of the marginal cost or yield curve determines how strongly the activities react to changes in paramters such as prices.

After its first applications in the late 1980s (Bauer and Kasnakoglu 1990), Howitt (1995) introduced the PMP approach to a wider audience, providing a generic way to obtain models that perfectly calibrate to observed activity levels. The initial applications, and many later too, introduced increasing marginal costs to obtain calibration, but provided no theory as to why marginal costs would increase. Heckelei (2002) proposed various ways to motivate the increasing marginal cost from an economic-theoretical perspective, and his theories involving risk behavior, i.e. that agents avoid overspecialization because they

\footnotetext{
8 This intuitive explanation holds true if also the opportunity cost of the limiting resources is considered.

9 Again, considering also opportunity costs of resources.
} 
are risk-averse, were later empirically implemented in Arata et al. (2017) and Basnet et al. (2021).

Apart from lacking a theory of why marginal costs increase, the standard PMP approach has other shortcomings. In the standard case, a single observation (a single base year) is available for defining two characteristics: the first and second derivatives of the objective function, typically the intercept and slope of a linear marginal cost function. Put differently: The condition that all activities must be equally profitable on the margin in the calibration point lets us define the marginal cost in that point, but not how the marginal cost changes if the activity level changes. Various parameter restrictions have been proposed as a remedy, effectively reducing the amount of information. The seminal paper by Howitt (1995) used an assumption about the relation of marginal to average costs, assuming that the observed cost was the average cost and then using the calibration condition to define the marginal cost, and Röhm and Dabbert (2003) introduced cross-activity restrictions to parameterize alternative but related activities jointly, even unobserved ones. Heckelei and Wolff (2003) introduced cross-sectional data, merging normative and positive methods in what Buysse et al. (2007) later termed "econometric programming models". That paper also pointed out that the marginal cost cannot be defined independent of the dual values of the constraints, in their case land rents. Jansson and Heckelei (2011) using panel data to estimate second order properties (supply elasticities) were probably the first to use more observations than there are activities to calibrate. Another source of second-order information regularly used is exogenous supply elasticities, and Mérel and Bucaram (2010) develop conditions under which exact calibration to exogenous elasticities is possible for certain common models.

Turning to the fisheries literature, we found only one application of PMP. Sweeney et al. (2017) adapted and applied PMP for a model of individual fishing vessels in Hawaii catching three different species. In their model, catch is a function of inputs via a Constant Elasticity of Substition (CES) production function. They simultaneously calibrate share parameters and scale of the CES function, an "unobserved value of catch" per vessel and target species, and the quota rent for each of three restrictions on catch, which are all assumed to be binding. The degrees-of-freedom problem ${ }^{10}$ that arises from more variables than calibrating equations being present is resolved by minimizing the sum across all vessels of squared differences between observed and model expenditures per target species, subject to first-order conditions and accounting constraints.

Data on landings and efforts rarely match quotas or restrictions exactly, and hence it is not always a-priori clear whether any given restriction is satisfied with equality and hence associated with a dual value, or if it is slack and thus with zero dual value. The possibility of many non-binding restrictions is rarely present in the modelling literature. Heckelei and Wolff (2003) model a single inequality that is unlikely to be zero. Sweeney et al. (2017) have several constraints, but assume a-priori that they are binding and associated with dual values. Complementary slackness conditions Eqs. (11)-(14) of the technical appendix) cause the optimality conditions defining possible optimal solutions to be nonconvex: it becomes a mathematical program with equilibrium constraints (Facchinei et al.

\footnotetext{
10 The authors don't mention any degrees of freedom problem. Technically, though, calibrating one activity variable requires adjusting just one parameter per activity, whereas the authors calibrate both a CES parameter and an"unobserved value of catch" parameter. The indeterminacy in how much each parameter should be adjusted is resolved by (indirectly) introducing additional information in the form of the requirement that the calibrated parameters imply minimization of the sum of squared deviations from a-priori given expenditures.
} 
1999). Jansson and Heckelei (2009) solve a calibration problem with many inequalities in a didactic-size spatial price equilibrium model of trade. We adapt that approach to a Bayesian setting and apply to our fisheries model.

\subsection{Our approach to Calibration}

Our model contains several unknown parameters to calibrate and uses observations with different units of measurement and errors. We assume that we have measurement errors on marginal costs, landings (determined by the marginal catch parameter $(\delta)$ ), the average engine power per segment, and the maximum number of days that fisheries under effort restrictions can go out in practice (days per vessel and year). To account for the situation that for some fisheries the regulated number of permitted fishing days may not be available due to factors such as weather conditions, we calibrate the number of fishing days available per season in each fishery. We also allow for an unobserved "optimization error" $\left(P M P_{f}\right)$ that is something else than a measurable variable cost or marginal catch effect. Clearly, the calibration condition that the marginal profitability of all fisheries must be equal is not sufficient to define all the unknown parameters. We therefore introduce additional (prior) information that helps us define all the parameters while also calibrating the model.

In order to utilize prior information on the distributions of the various measurement errors and on the available fishing days, we develop a Bayesian calibration method. The intuition behind the Bayesian method is that we do have a certain space, say $\Omega$, of parameters (for the five parameters variable costs, marginal catches, engine power, available fishing days, and optimization errors), defined by the Karush-Kuhn-Tucker (KKT) conditions, where any parameter vector $\theta \in \Omega$ would perfectly calibrate the model. E.g. would a large PMP term and a small deviation from observed landings calibrate the model equally well as a small PMP term and a large deviation from observed landings. Our calibration procedure introduces a probability density function $h(\theta)$ and picks as the point estimate the parameter that calibrates the model and has the highest density value, i.e. we solve $\max h(\theta): \theta \in \Omega$. We maximize the joint probability density of the five vectors of parameters mentioned above from their prior densities, conditional on the observed data, and subject to the KKT conditions being satisfied. If the prior density is normally distributed this is equivalent to minimizing the weighted sum of squared deviations from the observations.

The prior distributions were assumed to be composed of the following independent distributions: the constant error term per FOC $\left(P M P_{f}\right)$, the difference between observed and modelled variable costs, the difference between observed and modelled landed catch, the deviation of engine power per segment from the observed average are normally distributed with zero mean and variances as described in Appendix "7." section. The effectively available season for regulated fisheries is beta distributed between zero and the number of calendar days in the season, with the mode at the number of fishing days in the season. For all prior distributions except the optimization error, the standard deviations were set to a specific share of the prior modes as listed in Table 4. For the optimization errors, for which we have no observations but the indirect requirement to fit the FOC, variance was set to ten times that of the average variable costs. Allegedly, our assignments of prior distribution parameters is subjective as regards e.g. precisions (variances). Nevertheless, the Bayesian approach lets us introduce such out-of-sample information in a formal and explicit way.

The complementary slackness conditions make the set $\Omega$ non-convex, meaning that it is such that on a line connecting two feasible points (a) and (b) there are no other points that are also feasible. An example would be: if a fishery limited by a catch quota appears 
to be highly profitable but does not fill the quota, the explanation can be that either (a) our costs are too low, the quota rent is in fact zero, or (b) the costs are correct, but there was a measurement error in landings and the fishery does in fact fill the quota, and the quota rent explains the high profitability. An intermediate solution where there is both a small quota rent (costs adjusted just a little) and a small adjustment in landings (quota not quite filled) is not permitted due to the complementary slackness conditions, because the quota rent can only exist if the quota is filled exactly. We must choose what to change: costs and quota rents or landings. We solve this by applying a sequence of smooth approximations: Initially, large violations, called complementarity gaps, of the complementary slackness conditions are permitted, making the problem convex but not representing an optimal solution of our fisheries model. By the example above, we initially permit solutions where there is both a quota rent and an under-filled catch quota, but at a small penalty. Then, in a sequence of solutions of the Bayesian calibration model, where each new solution uses the previous solution as start value, the complementarity gap is increasingly penalized in the objective function until the gap - and also the penalty -becomes zero. This procedure is described in the technical appendix "7." section.

\section{Data, Calibration Results, and Approach for Sensitivity Analysis}

\subsection{Data}

Our fleet data are from 2012 and were collected by the SwAM within the EU's mandatory Data Collection Framework (DCF, Commission of the European Communities Decision 2010/93/EU). This contains the fishers' logbooks, which report fishing effort, gear, area, landed catch, and days with seal interaction. Furthermore, the DCF requires countries to collect economic information such as variable and fixed costs used in the model implementation (STECF 2018). Fish prices are from official sales notes at first sales (European Commission 2009). Data on costs for seal damage to fishing gear were collected for 2013/14 in a survey of Swedish fishers conducted by Waldo et al. (2020a, b) and the population of seals is estimated for 2013 in Hansson et al. (2017). With data from multiple sources the years differ slightly. Since the seal data is from a year after the other data and the seal population is growing the costs might be slightly over-estimated. For comparison, the growth of the seal population is about 5\% per year (SwAM, 2019).

Fleet data were aggregated to 247 different fisheries (combinations of vessel segment, gear, and fishing area) operated by 24 segments (see Table 5) that spent 68,086 days at sea and caught 44 species of fish. Aggregated this way, the data set contains 1,649 landed catches (combinations of fishery and landed species). The average landed quantity was about 81 tons per year, but the variation across fisheries and species is very large (standard deviation $=902$ ), reflecting the fact that a few large pelagic trawlers account for a large share of the total catch. 


\subsection{Calibration Results}

In order to evaluate how well our calibrated model fit observations, we computed three versions of the Root Mean Squared Deviation $\left(\mathrm{RMSD}^{11}\right)$, and the Pearson Coefficient of Correlation $\left(\mathrm{PCC}^{12}\right)$. These statistics are summarized in Table 1. RMSD is the square root of the average square of deviations between observations and fitted model values; a lower value is better. Since our model contains measurement errors-i.e. there are deviations permitted on several variables with different units, such as landed catch and variable costs-a plain RMSD does not say much about the relative fit. Therefore, we also computed the normalized RMSD (NRMSD), which is the RMSD divided by the mean of observations. For the FOC error there were no observations, so normalization was done with average marginal revenue instead.

NRMSD indicates that the season length (maxEffFishery) is very well fitted, and that the engine power follows the prior distribution exactly. Looking at the results for individual fisheries and segments, we note that season length is only binding in three out of 247 fisheries modelled, and that is for three fisheries catching vendace. Since vendace is caught during a limited season for its roe, it is plausible that the season length actually poses a limitation in this fishery.

The mean calibrated average variable costs $(A V C)$ is lower than the prior (observed) mean, whereas calibrated landings are higher than observed mean, both suggesting that the profitability of the fisheries generally is too low for explaining observed fishing efforts. For AVC, the NRMSD is small ( $12 \%$ of mean), indicating that the calibrated values follow data closely. The high correlation is also confirmed by the high value of PCC: The maximum possible value is 1 , and the lowest possible value is 0 . We found values very close to $1^{13}$ (see bottom row of Table 1).

Table 1 Summary of estimates. Average variable costs $(A V C)$ and FOC error in 1,000 euros per day, landed catch in 1,000 metric tons, maxEffFishery in days per vessel

\begin{tabular}{llllll}
\hline & Landings & AVC & maxEffFishery & Kwh/vessel & FOC error (PMP) \\
\hline $\mathrm{n}$ & 1649 & 247 & 247 & 24 & 247 \\
Mean of estimates & 83.403 & 17.778 & 242.749 & 295.231 & -7.968 \\
Mean of observations & 80.849 & 18.575 & 242.885 & 295.231 & 0 \\
Standard dev. of estimates & 917.060 & 23.914 & 71.707 & 0 & 21.320 \\
Standard dev. of observations & 901.866 & 24.818 & 71.274 & 0 & 0 \\
RMSD & 106.851 & 2.272 & 1.373 & 0 & 22.719 \\
NRMSD & 1.322 & 0.122 & 0.006 & 0 & 1.143 \\
RMSWD & 0.265 & 0.299 & 0.326 & 0 & 0.945 \\
PCC & 0.993 & 0.997 & 0.999 & 1 & 0 \\
\hline
\end{tabular}

RMSD Root Mean Squared Deviation; NRMSD Normalized Root Mean Squared Deviation; RMSWD Root Mean Squared Weighted Deviation; PCC Pearson Coefficient of Correlation

${ }_{11} \mathrm{RMSD}=\sqrt{\frac{\sum_{i}\left(x_{i}-y_{i}\right)^{2}}{n}}$, c.f. Mean Square Error [MSE] in Greene, 2003).
$12 \mathrm{PCC}=\frac{\sum_{\sum_{i}\left(x_{i}-\bar{x}\right)\left(y_{i}-\bar{y}\right)}}{\sqrt{\sum_{i}\left(x_{i}-\bar{x}\right)^{2}} \sqrt{\sum_{i}\left(y_{i}-\bar{y}\right)^{2}}}$

13 A PCC close to 1 indicates that the fitted values follow observations closely. This could indicate that there are many parameters fitted relative to the amount of information entering in the form of observations or prior information, so that "almost any" behavior can be replicated: i.e., the model could be over-parameterized. More years of observations would probably give us lower PCC values, while also introducing further complexities such as dynamics and expectations. 
For landings, the NRMSD is above 1, suggesting that the average error is larger than sample mean. However, NRMSD does not take into account that landings consist of very large landings mixed with tiny ones, so that the absolute error in a large landing easily can be 10 or 100 times a small landing, even if it is small in relation to the relevant large landing. For the optimization error, i.e. the constant PMP term, which has a prior mean of zero, it is not possible to compute the RMSD statistics. In order to put the importance of the optimization errors in context, we compare each error term to the marginal revenues of the relevant fishery and compute the three RMSD statistics that way. The NRMSD of more than 1 means that it is on average larger than the marginal revenue, and its negative mean value suggests that additional revenues per fishery need to be introduced in order for our model to properly explain observed fishing patterns. This fits well with the observation that many fisheries, in particular smaller ones, appear to have very low or even negative profitability.

Since NRMSD does not take into account that some parameters are considered less accurate than others a priori, e.g. the error in a large landing such as herring from a pelagic trawler is arguably much more variable in absolute terms than that of a small landing such as the catch of pike or perch from a small scale coastal fishery. A larger prior standard deviation gives less weight in the estimation criterion, but that is not reflected in NRMSD. This can be taken into account if, when computing the RMSD, we consider a weighting $\frac{1}{\sigma^{2}}$, where $\sigma^{2}$ is the prior variance. This statistic is similar to the Mean Squared Weighted Deviation analyzed by e.g. Wendt and Carl (1991). To make it comparable to our other statistics we take its square root (RMSWD). Intuitively, it weighs each deviation from the prior mode by the inverse prior variance, so that a large deviation is considered less severe if the prior variance is large and vice versa. Therefore, the RMSWD tells us something about how well the estimates follow the prior distribution and is also the metric that is minimized in the estimation for normally distributed variables (but not for beta-distributed ones). The results indicate that landed catch, variable costs are in fact equally well fitted. However, the average FOC error (PMP term) weighted this way is smaller than NRMSD but still high relative to its prior distribution ( $94.5 \%$ of the mean marginal revenue). This result reflects our assumption, introduced in the prior standard deviations, that the FOCs convey less reliable information than the observations of variable costs and therefore carry less weight in the calibration objective function.

\subsection{Approach for Sensitivity Analysis}

A sensitivity analysis is performed for three important parameters; the slope of the variable cost curve ( $v c b_{f}$ in Eq. 1), the elasticity of the catch function ( $\beta$ in Eq. 2 ), and the price of fish ( $p_{f, s}$ in Eq. 1). These are key parameters in the model and represent both the cost and revenue components of the profit maximization problem in Eq. 1. In the sensitivity analysis each parameter can be either Medium (same as in main model), Low (-25\%), or High $(+25 \%)$. Each scenario is run for all possible combinations of Medium, Low, and High for the three parameters, corresponding to 27 separate model runs per scenario (see scenarios below). For each run the model is calibrated to represent the baseline scenario and then the other scenarios are re-simulated using the changed parameters. The results from the sensitivity analysis are presented as error bars in the diagrams in the result section. 
Table 2 Scenarios

\begin{tabular}{ll}
\hline Scenario & Description \\
\hline 1. Baseline-Current seal population & The seal populations are fixed at the current population status. \\
& Economic compensation is 1.5 million euros per year \\
2. Seals at carrying capacity & Seal populations are assumed to reach carrying capacity. This \\
& is modelled as a 100\% increase in the seal populations, which \\
& implies that seal costs and seal damage would increase by 100\%. \\
& Economic compensation remains at baseline \\
3. Minimum GES seal stock & Lethal methods to reduce seal populations by 75\%. Seal costs and \\
& seal damage are reduced accordingly. Economic compensation \\
& remains at baseline \\
4. Increase economic compensation & The seal population is fixed at its current population status. Eco- \\
& nomic compensation increases by 100\% \\
5. Seals at carrying capac- & Seal populations increase 100\%. Seal costs and damage increase \\
ity + Increased economic compensa- & 100\%. Economic compensation increases by 100\% \\
tion & \\
6. Regional seal growth & Seal populations increase by 400\% on the southern Swedish coast. \\
& Seal populations increase 50\% in all other areas. Economic \\
& compensation remains at baseline
\end{tabular}

\section{Scenarios}

Six different scenarios are used for illustrating how the model can be used for policy analysis. The scenarios are defined from existing seal and fisheries management objectives where seal populations are either at 2012 levels, at carrying capacity (expected future seal population at current management) or at GES (minimum population size in the implementation of the EU habitats directive), and where fishers are economically compensated for the seal presense at different levels. Note that the scenarios do not provide information about the total welfare effect of the policies since benefits outside fishing such as seal watching and nature conservation are not included in the model (Table 2).

The first scenario is the baseline scenario to which the model is calibrated and thus represents the 2012 seal population and fishing fleet. The seal population in this scenario is 43000 individuals which is larger than the GES population of 10000 but lower than the carrying capacity of $88000-100000$. The second scenario is based on the 2012 Swedish management that allowed the seal population to grow towards carrying capacity. This is assumed to imply a doubling of the 2012 seal population (note that due to factors such as climate changes, it is not certain that the Baltic can carry the stock sizes found in Harding and Härkönen 1999). A larger seal population implies more seal predation of fish from the gear, and thus less fishing effort and lower profitability is expected. In the third scenario, the seal population is reduced to GES level of 10,000 seals, as discussed above. Thus, in this scenario the number of seals is reduced by $75 \%$ from the approximately 40,000 individuals in 2012. A smaller seal population implies less seal predation of fish from the gear and thus a larger fleet with higher profitability is expected.

In the baseline scenario, fishermen receive economic compensation for lost catch of 1.5 million euros. According to SwAM (2012), seal compensation was approximately half of estimated seal damages in the studied period. In scenario 4, economic compensation is 
increased by $100 \%$, to 3 million euros. ${ }^{14}$ In scenario 5 , the seal population is assumed to double, which implies carrying capacity, and economic compensation is assumed to double as well. Scenarios 2-5 have an implicit assumption that the seal population changes proportionally in all areas. Scenario 6 introduces a regional dimension into the analysis. Seal populations are assumed to grow more in the southern part of the analyzed area, which is less exploited by seals (Helcom 2018). In scenario 6 the seal population is expected to increase by $400 \%$ in this area ${ }^{15}$ and only by $50 \%$ in the rest of the areas. This is a rough estimation of changes in the population, but it reflects an important dimension: fisheries along the Swedish south coast are currently under strong pressure from increased seal interaction and seal-proof gear is not yet fully developed to prevent predation.

\section{Results}

The results are presented below aggregated over vessels using active/passive gear, different kinds of passive gear, regions and fleet segments. Each figure contains error bars showing the highest and lowest value from the sensitivity analysis.

\subsection{Aggregate Results for Vessels Using Active and Passive Gear}

In Fig. 1, the days at sea for each scenario are presented aggregated to vessels using passive gear (nets, hooks, and pots) and vessels using active gear (trawl). Although only passive gear is affected by seals, there are two reasons for including vessels using active gear in the analysis. The first is that some of the vessels have minor fisheries with passive gear that might be affected by seals. The second reason is that there might be interactions between vessels using passive and active gear through quotas. If fishing with passive gear decreases due to increased seal populations, there will be more quota available for other vessels that might increase their fishing. The magnitude of these effects is not known a priori to the empirical estimates. Figure 1 shows the days at sea for vessels using active and passive gear for each of the scenarios.

As is clear from the figure, vessels using active gear are very stable over the scenarios. Based on this, the rest of the presentation only considers vessels using passive gear, unless otherwise stated.

Scenario 1 (S1) is the reference scenario (baseline), showing the baseline number of days at sea. In scenario 2, where seal populations are allowed to grow to carrying capacity, effort is reduced by 4,922 days (11\%). However, total catches are reduced by $26 \%$,

\footnotetext{
14 According to current legislation, seal compensation is defined as a subsidy of minor significance which means that a total of about 30,000 euros per 3-year period is allowed (SFS 2008:437): i.e. 10,000 euros per year on average. Considering that the current fleet consists of over 700 small-scale vessels, a total seal subsidy of 3 million euros is within the legal limits.

15 This is based on the historical change in grey seal populations from 2002 to 2012 in two seal spotting sites in the southern Sweden (Utklippan and Måkläppen; SwAM, 2014). During this period the grey seal population in the entire Baltic Sea roughly doubled.
} 


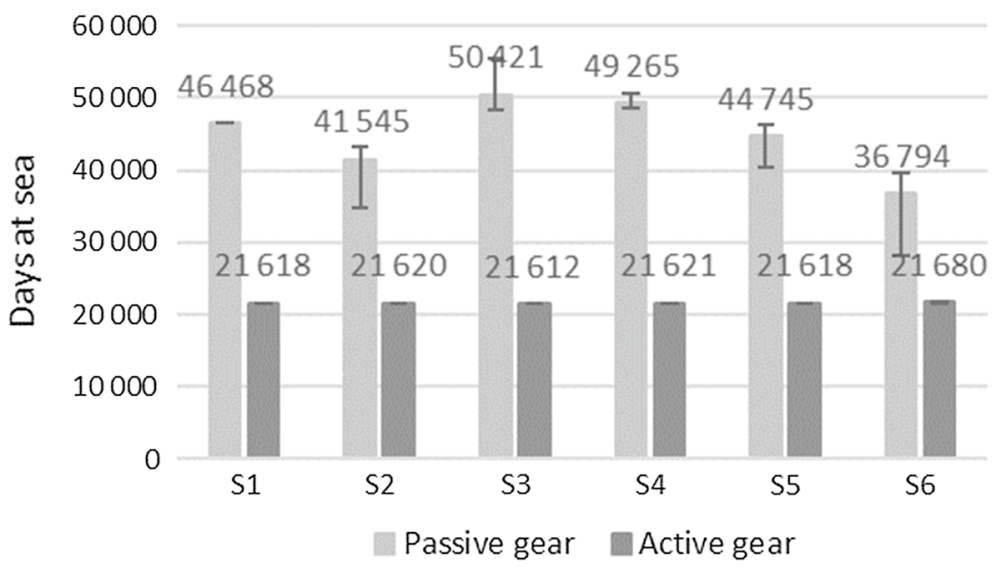

Fig. 1 Days at sea per year for vessels using passive and active gear

since species such as cod and herring that are caught in larger volumes are heavily affected by the changes. Two scenarios show a fishing effort higher than baseline. These are the scenarios with lower seal abundance (S3) and with the 2012 seal abundance but higher economic compensation (S4). Combining a high seal population at carrying capacity with corresponding increases in economic compensation (S5) will imply less fishing than in the reference scenario but more fishing than higher seal abundance without additional compensation (i.e., compared to S2). The regional scenario (S6) has the lowest fishing activity, which could be explained by seals primarily increasing in areas with large fisheries for species where no seal-proof gear has been developed and where the damage caused by additional seals thus is larger.

From the sensitivity analysis it is clear that the results for vessels using active gear are very stable. For the vessels using passive gear, some scenarios are more sensitive to changes in the parameters than others. Despite this, the results are robust in the sence that all scenarios that predict reduced days at sea compared to the baseline (S1) also do so in all model runs in the sensitivity analysis. Also, all scenarios that predict an increase in days at sea compared to $\mathrm{S} 1$ also do so in all model runs in the sensitivity analysis.

Turning to the economic performance of vessels using passive gear, Fig. 2 shows that profitability in the sector is negative. Negative profitability in small-scale fisheries is not unusual in Europe (STECF 2018). In the baseline, the loss is approximately 2 million Euro.

In scenario S2 the loss is 3.3 million Euro, a decrease in profitability of over $60 \%$ compared to the baseline scenario. A decrease in the seal population (S3) would significantly reduce the losses in the sector. These results indicate the high impact that seals have on the sector. Increasing subsidies in S4 increases profitability by about 0.9 million euros per year, which is less than the 1.5 million euros subsidy increase. An increased subsidy combined with increased seal populations (S5) results in an overall lower profitability in the sector. Thus, adding compensation in proportion to the change in seal abundance does not fully compensate for losses due to increased seal interaction. Economic losses are greatest in scenario S6, which again reflects the high impacts seals have along the southern Swedish coast compared to other areas. 


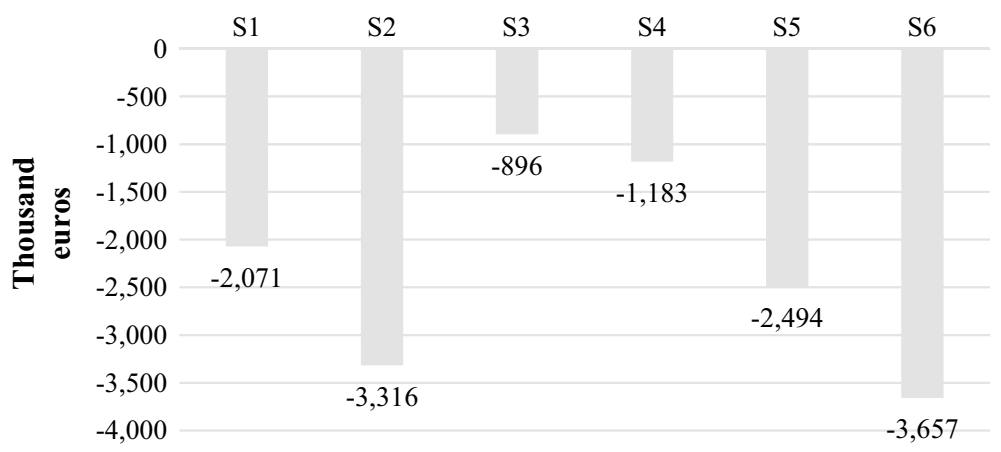

Fig. 2 Economic performance (thousands of euros), passive gear

\subsection{Results by Gear}

Gear usage for each of the scenarios is shown in Fig. 3. In the figure, effort in fisheries using passive gear-nets, longlines, pots, and traps-is aggregated to two groups: nets and longlines, and pots and traps. The reason for this is that fish are more protected in pots and traps than in the other gear and could thus be expected to be less affected by seal predation.

As expected, Fig. 3 shows that nets and longlines are more affected by seal policies than pots and traps. However, pots and traps are also affected to some extent. Salmon (Salmo salar) and eel (Anguilla anguilla) are attractive prey, and seals are able to break some of the traps, while pots for Norway lobster are less affected, since seals do not prefer to prey on shellfish.The result in scenario 6 is sensitive to changes in model parameters and in the worst case prediction the days at sea for net and hooks are reduced with more than 60 percent.

\subsection{Results by Region}

A regional analysis shows major differences between the two fishing regions in Sweden: the Baltic Sea and the North Sea. Since regional fisheries include both active and passive gear, both are included in Fig. 4.

From the figure it is clear that it is the Baltic Sea fisheries that are affected by seal policies. North Sea fisheries are more or less unaffected, which is due both to a history of using active gear that does not interact with seals and its large fishery for Norwegian lobster, which is also largely unaffected by seals for the reason mentioned above.

\subsection{Results by Segment}

In this section the results are presented at the segment level for vessels using passive gear. The fleet segments used in the model (Table 5) are aggregated to four segment types for presentation purposes: vessels below $12 \mathrm{~m}(\mathrm{PAS}<12)$, vessels above $12 \mathrm{~m}$ (PAS > 12), vessels targeting Norwegian lobster (PAS_NorwLobst), and vessels targeting salmon and vendace (PAS_SAL_VEND). The latter are typically located in the northernmost part of the Baltic Sea. Figure 5 shows days at sea for each segment. 


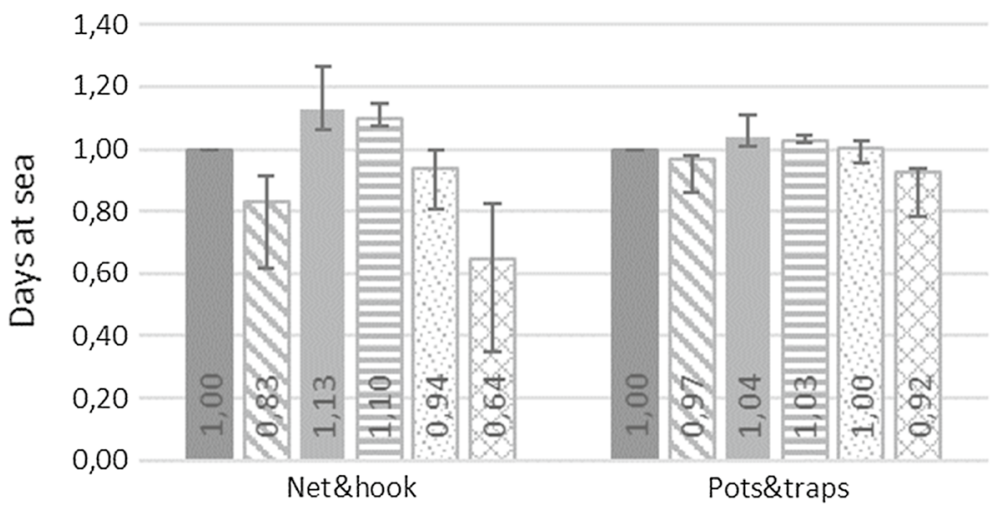

$\square \mathrm{S} 1 \square \mathrm{S} 2 \square \mathrm{S} 3 \boxminus \mathrm{S} 4 \mathrm{~S} 5 \square \mathrm{S} 6$

Fig. 3 Days at sea by gear-type

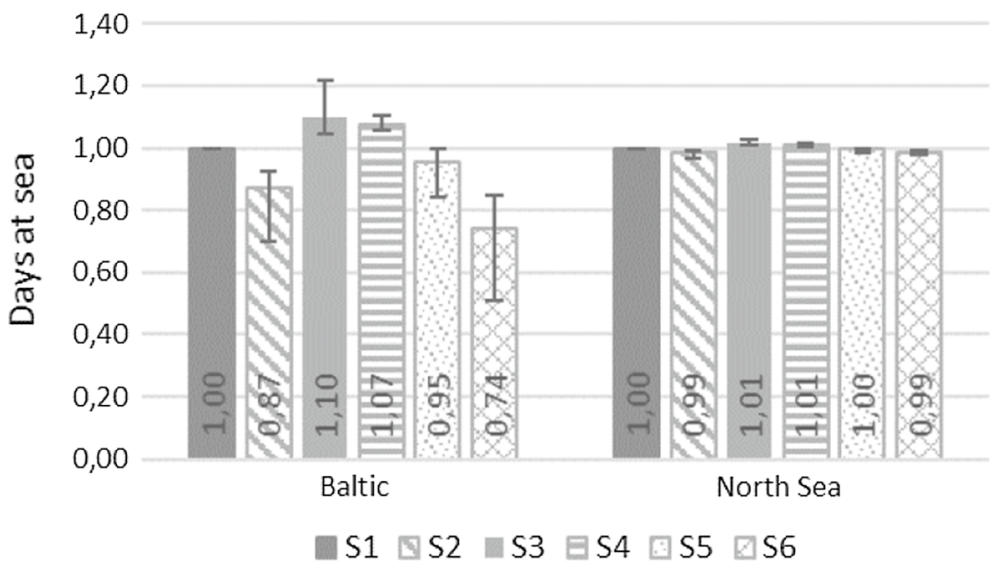

Fig. 4 Days at sea for fisheries in the Baltic Sea and the North Sea (both active and passive gear)

An initial observation is that the segment targeting Norwegian lobster is more or less unaffected by seal management. The segment most affected is passive vessels over $12 \mathrm{~m}$ (PAS $>12$ ), where about one-third of the fishery would not take place if seals were at carrying capacity (S2). A major part in this segment is cod fisheries in the Baltic Sea using gill nets and longlines. This is one of the fisheries that have most interactions with seals. The results for PAS > 12 are, however, sensitive to the model parameters and is considered less certain than most of the other results in the analysis. Vessels targeting salmon and vendace show surprising results, since they increase effort in scenarios where the other segments reduce their, and vice versa. This segment is active in a part of the Baltic Sea where seals have been present for decades. Thus, they are better equipped for coping in an ecosystem with high seal abundance. In the model, they have smaller costs for seal interactions. Therefore, when the other segments reduce their effort due to seals, they can benefit from additional quotas (the shadow price for quota is reduced). 


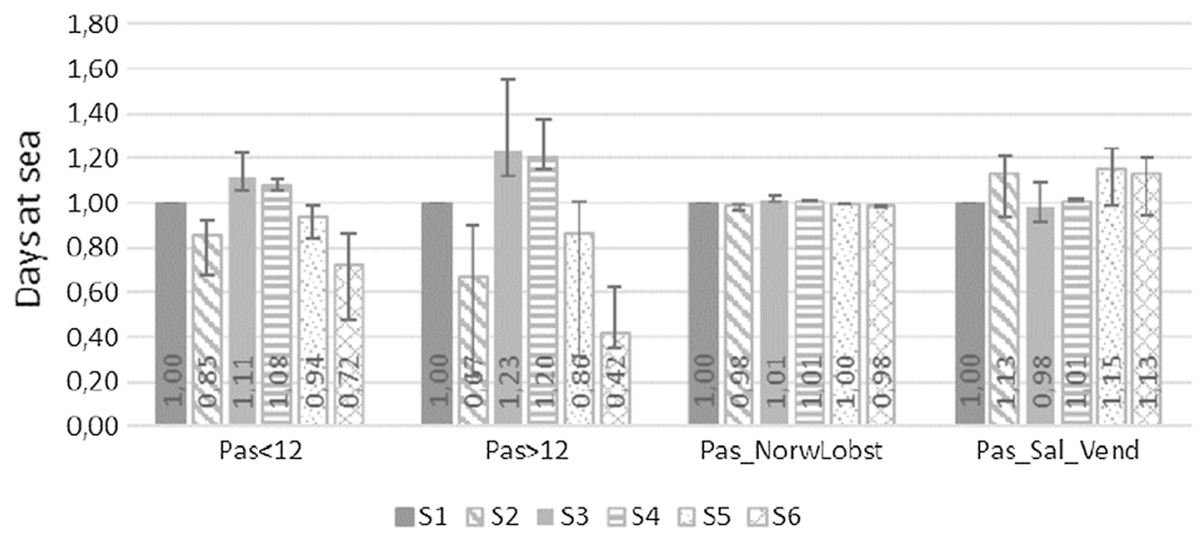

Fig. 5 Days at sea by fleet segment

The economic performance per fleet segment is presented in Table 3. As is clear from the table, negative profitability stems from the segment with the smallest vessels $(<12 \mathrm{~m})$. This is the largest segment when measured in terms of number of vessels. Many of these are operated by part-time fishers and fishers that also receive retirement income. Thus, the low profitability might be a symptom of fishers that operate their vessels not entirely for commercial purposes. The other fleet segments have positive profits, and in most cases this is true for all seal scenarios.

\section{Discussion}

In this study we develop a new model of commercial fisheries with multiple restrictions (quotas, effort) that are not all binding. The model is calibrated to observed data with methods inspired by agricultural PMP models. In contrast with previous approaches, the novel calibration method determines which quotas and effort restrictions are binding in the baseline. The model fits into the framework of integrated ecological-economic fisheries models (IEEFM) for policy purposes outlined in Nielsen et al. (2018). Most IEEFM focus on a single sea area, where both fisheries and stock development are modelled over time (dynamic modeling). Our approach differs from this by focusing on a multitude of choices of gear, areas, and target species available to the fleet in a given time period. Fishers make economic decisions based on the fleet structure and fishing opportunities in different areas, and thus a natural starting point for an economic analysis is the fleet and not a specific area that could contain vessels from fleets fishing part time in the area and part time in other areas.

The empirical application shows a negative impact of seals on fisheries using passive gear, while the fisheries using active gear (trawls) are more or less unaffected. This is primarily due to seals not interacting with trawls, but there is also an interesting lack of secondary effects on the trawlers. With less fishing taking place by passive gear, quotas is expected to be available for other fisheries. However, many of the fish species eaten by seals (e.g. perch, pikeperch, eel) are not caught by trawlers and will thus not affect their fishery. Other species, such as cod, are targeted by both passive and active gear. However, 
Table 3 Profit (thousands of euros) by fleet segment

\begin{tabular}{lllllll}
\hline & S1 & S2 & S3 & S4 & S5 & S6 \\
\hline PAS $<12$ & -3644 & -4441 & -2773 & -3068 & -3969 & -4587 \\
PAS $>12$ & 789 & 616 & 969 & 940 & 721 & 525 \\
PAS_NorwLobst & 458 & 409 & 503 & 482 & 447 & 415 \\
PAS_SAL_VEND & 327 & 100 & 405 & 463 & 308 & -11 \\
\hline
\end{tabular}

the cod quota is not fully utilized even in the reference scenario and thus not a binding constraint for the trawlers; additional quota will not increase fishing. On the Swedish west coast, cod is often caught together with sole in multi-species fisheries. The sole quota is binding in the model and thus restricts the cod fishery in the area. In the sceanrios, the fishers using passive gear do not reduce sole catches and the quota available for trawling will therefore not increase. Thus, the limited secondary effects can be explained by several specific circumstances concerning which species seals affect and the role of the quotas for these species.

Focus in the model is on short-term effects on the fishing industry. This provides information on how a fixed fleet is affected by policy changes, but does not estimate an optimal fleet size or how a policy will change the fleet composition. Some policies, e.g. Individual Transferable Quostas (ITQs), might cause rapid changes in the fleet structure (Brinson and Thunberg 2016) but for many other policy measures a high job satisfaction of local fishers might keep them from exiting the sector despite unfavorable economic conditions (Pollnac et al. 2015). Thus, focus on a fixed fleet might not reflect the expected development for some policy changes but do so for others. The application to the seal-fishery interaction primarily concerns coastal fishers with low profitability but a strong cultural link to the profession, which is likely to reduce the willingness to exit the industry.

The static nature of the model implies that no dynamic interactions (e.g. between fishing effort and stock development) are modelled. This includes the interaction between seals and commercial fish species. Seals prey on important commercial species such as cod and herring (Nilssen et al 2019; Hansson et al. 2017) which implies a competition for fish in addition to the modelled interaction with seals eating directly from the gear. The competition for fish also affects gear such as trawls that are not primarily targeted by feeding seals. Thus, not including this effect in the model will underestimate the total effect of seals on the fishery. The size of this effect depends on the seals' diet and the abundance of seals. Costalago et al. (2019) find in an ecosystem model that cod biomass in the Baltic Sea (at a fishing mortality of Fcod=1) is $6 \%$ lower with seals at carrying capacity compared to an ecosystem without seals. Cod is one of several commercial species and of course seals will also affect other stocks depending on their dietary choices. E.g. do Costalago et al. (2019) base their study on a larger share of herring in the diet than found in Nilssen et al. (2019).

An additional factor not included in the model is parasite infections (cod worm (Pseudoterranova decipiens) and liver worm (Contracaecum osculatum)) caused by seals (Eero et al. 2015). Parasites have two effects on the fishery; the first is lower general conditions of the cod which reduces the nutrition status of the fish (Sokolova et al. 2018) which in turn might have negative effects on stock development. The second effect is the risk of consumers finding parasites in fish filets. Removing parasites is costly and fishers might not find all parasites which reduces the attractiveness of the fish on the market. If parasite infections were included in the model, the expected result would be a larger impact on the 
fishing industry compared to the presented model results. Thus, with both competition for fish resources and parasite infections having a negative impact on the industry, it is clear that the model results will underestimate the aggregate impact of seals.

Reducing the seal population will benefit the fishing industry, but will also come with a cost for society. A reduction of the seal population from over 40000 seals to for example the minimum biological limit of 10000 is a major commitment that will be costly in economic terms and at the same time highly controversial (Jackman et al. 2018). However, support for population control can be found in Swedish fishing communities (Waldo et al. $2020 \mathrm{a}, \mathrm{b}$ ) and the first attempts to allow hunting for population control has been adopted in Swedish seal management (Swedish EPA 2020). On the other hand, viable seal populations do not only imply costs but also provide a value to society. This includes existence values, the value of being able to watch seals in their natural environment, and possible values of recreational hunting. These are important pieces of information necessary for evaluating the total costs and benefits of different seal management options that are not included in the analysis. Seal watching is currently not a major tourist attraction in the region, but might might grow in the future (see e.g. Bosetti and Pearce 2003; Boncoeur et al. 2002; Ryan et al. 2018). Recreational hunting for large mammals is valuable, but seal hunting is both difficult and controversial (Nunny et al. 2018) which might reduce the value.

Since the small-scale fishing fleet is a minor contributor to GDP, the consequences of seal-fisheries interactions are small if only viewed as the economic performance. However, fisheries management has a clear objective to keep the small-scale fleet active to protect cultural values and local landings. The reduced profitability as estimated by the model might thus be viewed a smaller issue than reduced effort which might reduce activity in traditional fishing communities. But the economic performance indicators are still important since they provide information not only on society's costs for seals, but also for the economic resilience of the fishing fleet. Attracting new generations of fishers will depend on the economic prospects, and existing fishers might leave if the economic return becomes too low.

\subsection{Summary of Empirical Results and Future Research}

The results show that seal populations at carrying capacity cause efforts in Swedish smallscale fisheries to decline by $11-21 \%$ (scenarios 2 and 6) and profits to be reduced by about 1.3 million euros from an already unprofitable level of -2 million euros. Two million euros could be considered a minor economic impact compared to the size of the entire Swedish fishing sector with yearly landings of about 100 million euros. However, the culturally important costal fleet is already today economically vulnerable and has been declining for decades leaving many traditional fishing communities with few fishers left (Waldo and Blomquist 2020). More research is needed to fill the knowledge gaps of benefits from e.g. seal watching and recreational seal hunting. This information is necessary for a full understanding of the costs and benefits of different management options for the seal-fishery interaction in the region. From a modelling perspective the calibration approach used can be further developed. E.g. using several years of data for the calibration would add information on how the fishing sector react to exogeneous shocks and prior information on existing quota prices could improve the calibration of quota rents. 


\section{Appendix A. Estimation}

The model is calibrated to the observed situation in 2012 (see Sect. 6). Calibration implies that we assume that the observed situation is an equilibrium that we want the model to reproduce. If the model is solved using the given data together with behavioral parameters (such as catch elasticities) from the literature, it is unlikely to reproduce the observed fishing pattern due to measurement errors and because the model is simplified compared to reality. In order to calibrate fishing effort, it is necessary to calibrate one term per firstorder condition. Since we believe that the data are subject to measurement errors, we prefer adjusting several parameters simultaneously in order to make better use of the various data sources. Jansson and Heckelei (2009) show, for a similar calibration of a spatial trade model, that an estimator allowing several parameters to change rather than calibrating the model by adjusting a single residual term is more efficient, albeit biased.

According to the terminology introduced by Buysse et al. (2007), our approach to calibration is that of Econometric Mathematical Programming, combining econometrics and mathematical programming. It resembles the method applied by Sweeney et al. (2017), but with simultaneous consideration of the fact that quotas and restrictions may or may not be binding. The calibration procedure is based on the necessary conditions for an optimal solution to the simulation model. This means that we form the Lagrangean function for the primary model given by the Eqs. 1-6 and derive the Karush-Kuhn-Tucker (KKT) conditions, consisting of first-order conditions (FOC) and complementary slackness conditions (CSC). Exact calibration is obtained if the KKT conditions are satisfied. The second order conditions are assumed to be satisfied due to the functional forms chosen and restrictions of certain signs. ${ }^{16} \mathrm{Eq} .8$ shows the full Lagrange function.

Lagrange function

$$
\begin{aligned}
& \mathcal{L}=\sum_{f, s}\left(p_{f s} L_{f s}\right)+\sum_{f} s u b s_{f} x_{f}-\sum_{f}\left(v c a_{f} x_{f}+\frac{1}{2} v c b_{f} x_{f}^{2}\right) \\
& -\sum_{\text {seg }} f c_{\text {seg }} \text { vessels } s_{\text {seg }}-\sum_{f} P M P_{f} x_{f}-\sum_{f, s} \lambda_{f, s}^{\text {landing }}\left[L_{f s}-\delta_{f s} x_{f}^{\beta_{f}}\right] \\
& -\sum_{\text {seg }} \lambda_{\text {seg }}^{\text {efRestrSeg }}\left[\sum_{f: I_{\text {seg }, f}} x_{f}-\text { vessel }_{\text {seg }} \text { maxEffSeg }_{\text {seg }}\right] \sum_{f} \lambda_{f}^{\text {effRestrFishery }}\left[x_{f}-\sum_{\text {seg }: I_{\text {seg }, f}} \text { vessel }_{\text {seg }} \text { maxEffFishery }_{f}\right] \\
& -\sum_{q s, q a} \lambda_{q s, q a}^{q u o t a}\left[\sum_{f, s: I_{q s, q a f, s}} L_{f s}-Q_{q s, q a}\right]-\sum_{e g, e a} \lambda_{e g, e a}^{\max e f f R e g}\left[\sum_{f: I_{\text {egea }, f}} x_{f} k w_{f}-\text { maxEffortPerGroup }_{\text {eg,ea }}\right]+\sum_{f} \pi_{f} x_{f}
\end{aligned}
$$

The first-order conditions (FOC) are as follows:

FOC with respect to effort $\mathrm{x}_{\mathrm{f}}$

$$
\begin{aligned}
s u b s_{f} & -v c a_{f}-v c b_{f} x_{f}-P M P_{f}+\sum_{s} \lambda_{f s}^{\text {landing }} \delta_{f s} \beta_{f} x_{f}^{\beta_{f}-1} \\
& -\sum_{s e g: I_{\text {seg,f }}} \lambda_{\text {seg }}^{\text {maxEffSeg }}-\lambda_{f}^{\text {effRestrFishery }}-\sum_{\text {eg,ea: } I_{\text {eg,ea } f}} k w_{f} \lambda_{\text {eg,ea }}^{\text {maxEffReg }}+\pi_{f}=0 \quad \forall f
\end{aligned}
$$

\footnotetext{
16 The model has monotonously increasing marginal costs and decreasing catch, making the objective function concave. However, this is not sufficient, since the catch quota restriction is nonlinear in fishery effort. Simulation tests indicate that our model is well behaved around the calibration point.
} 
This condition states (if the positive terms are taken first) that the marginal value of additional landed catch, plus subsidies, must equal the marginal cost plus the PMP term plus the shadow costs of quotas, season length, and effort restrictions. The various lambdas are the Lagrange multipliers associated with each restriction, while the $\pi_{f}$ is the Lagrange multiplier associated with the condition that for each fishery, effort $E_{f}$ has to be non-negative. ${ }^{17}$

FOC with respect to landed catch $\mathrm{L}_{\mathrm{fs}}$

$$
p_{f s}-\lambda_{f s}^{\text {landing }}-\sum_{q s, q a: I_{q s, q a f, s}} \lambda_{q s, q a}^{q u o t a}=0
$$

$\lambda_{f s}^{\text {landing }}$ is the marginal value of catch, and $\lambda_{q s, q a}^{q u o t a}$ is the quota rent or cost associated with binding landed catch quotas.

The CSC generally take the form $g(z) \lambda=\delta$, where the function $\mathrm{g}(\mathrm{z})$ is the relevant inequality constraint, $\lambda$ is the associated Lagrange multiplier, and $\delta$ is the complementarity gap, which is zero when the complementarity is satisfied and is otherwise something nonnegative. The solution method described below implies penalizing the complementarity gaps until they become zero.

CSC for fleet capacity

$$
\left[\text { vessels }_{\text {seg }} \text { maxEffSeg }_{\text {seg }}-\sum_{f: I_{f, \text { seg }}} x_{f}\right] \lambda_{\text {seg }}^{\text {maxEfSeg }} \leq \delta_{\text {seg }}^{\text {maxEfSeg }}
$$

CSC for restriction per fishery

$$
\left[\sum_{\text {seg: } I_{\text {seg.f }}} \text { vessels }_{\text {seg }} \text { maxEffFishery }{ }_{f}-x_{f}\right] \lambda_{f}^{\text {effRestrFishery }} \leq \delta_{f}^{\text {effRestrFishery }}
$$

CSC for effort regulation

$$
\left[\text { maxEffortPerGroup }_{\text {eg,ea }}-\sum_{f: I_{\text {eg,eaf }}} x_{f}\right] \lambda_{\text {eg,ea }}^{\text {maxEffReg }} \leq \delta_{e g, e a}^{\text {maxEffReg }}
$$

CSC for landing quotas

$$
\left[Q_{q s, q a}-\sum_{f, s: I_{q s, q a f, s}} L_{f s}\right] \lambda_{q s, q a}^{q u o t a} \leq \delta_{q s, q a}^{q u o t a} \forall q s, q a
$$

The model thus contains four groups of inequality constraints (three types of effort restrictions plus the landing quotas), where we cannot always say a priori if they should be binding - and hence have a dual value present in the first-order conditions - or if they are slack. The presence of the CSC makes the calibration problem more difficult to solve, as it becomes a mathematical program with equilibrium constraints (MPEC) (Facchinei et al. 1999). The solution developed here is based on stepwise smooth approximations with a penalty function proposed by Ferris, Dirkse, and Meeraus (2002).

We assumed that observations of variable costs and catches might contain errors, but that the errors in observations of fishing effort and number of vessels can be neglected (due

\footnotetext{
17 In the calibration, we only consider fisheries with non-zero effort, and hence $\pi_{f}$ is omitted from this point on.
} 
to regulatory reporting requirements and surveillance). The parameter maxEffFishery lim- $_{f}$ its the number of days a vessel can be active in a fishery (e.g. due to season length), but the existing data on this are imprecise. ${ }^{18}$ Furthermore, the parameter $P M P_{f}$, is considered to be an additive error term, insofar as FOC cannot be observed but has to be estimated. We want to make changes that are "as small as possible," and in order to define what is small for variables and parameters measured in different units, we cast the calibration problem in terms of a Bayesian estimation problem. This allows us to convert all adjustments into probability density values. We use the variables and parameters that maximize the joint probability density as our estimates: i.e., the combination of values that are "most likely" as measured against a priori density functions while satisfying the FOC.

In general, we assumed all error terms and parameters to be normally distributed. ${ }^{19}$ For

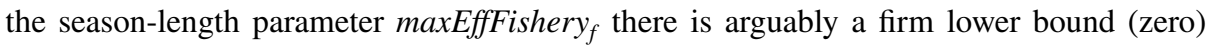
and an upper bound (365 days at most), and thus a beta-density is more appropriate. Standard deviations for the a priori distributions cannot be obtained from available empirical sources, and we therefore had to use assumptions as reported in Table 4. This means that the estimator may, for instance, reduce season length for a fishery so it becomes binding and a dual value appears in the first-order condition, if this helps explain observed fishing effort better than adjustments in costs or the PMP term.

The stepwise smooth approximations mean that the estimation criterion function is augmented with a penalty function that penalizes the existence of complementarity gaps in the solution. The weight of the penalty function is initially very small, but iteratively increases until all complementarity gaps disappear. The estimation criterion function including the penalty function is given by Eq. 15 .

The estimation criterion, to maximize, is derived from the logarithm of the product of all the prior density functions. The first four terms relate to normally distributed priors, where parameters are given in Table 4 and the weights are computed as $\frac{1}{2 \sigma^{2}}$ where $\sigma$ is the standard deviation. The fifth term is the logarithm of the beta density function for maxEffFishery after scaling it so that it falls into the interval $(0,1)$. A $\overline{b a r}$ symbol indicates the prior mean, typically equal to the observed value.

Estimation criterion function

$$
\begin{aligned}
& -\sum_{f} \text { weightAC } C_{f}\left(v c a_{f}+\frac{v c b_{f} x_{f}}{2}-\overline{A V C_{f}}\right)^{2} \\
& -\sum_{\text {seg }} \text { weight } K w_{\text {seg }}\left(k w_{\text {seg }}-\overline{k w}_{\text {seg }}\right)^{2} \\
& -\sum_{f} \text { weightPMP }\left(P M P_{f}-0\right)^{2} \\
& \max \quad-\sum_{f s} \text { weightLandings } f_{f s}\left(L_{f s}-\bar{L}_{f s}\right)^{2} \\
& +\sum_{f}\left(\alpha_{f}-1\right) \ln \left(\frac{\text { maxEffFishery }_{f}}{\text { maxEffFishery.up }_{f}}\right)+\left(\beta_{f}-1\right) \ln \left(1-\frac{\text { maxEffFishery }_{f}}{\text { maxEffFishery.up }_{f}}\right)
\end{aligned}
$$

18 We also have the opportunity to calibrate the $k w_{f}$ parameter so the model is able to reflect effort regulations. E.g., effort regulation might be binding in practice, but due to administrative regulations, some "effort days" are available in the system, which makes the model restriction non-binding.

${ }^{19}$ We have tried gamma distributed priors, with the support $[0, \infty]$ and modal values given by observations where available, but that does not seem to bring any clear benefits. 


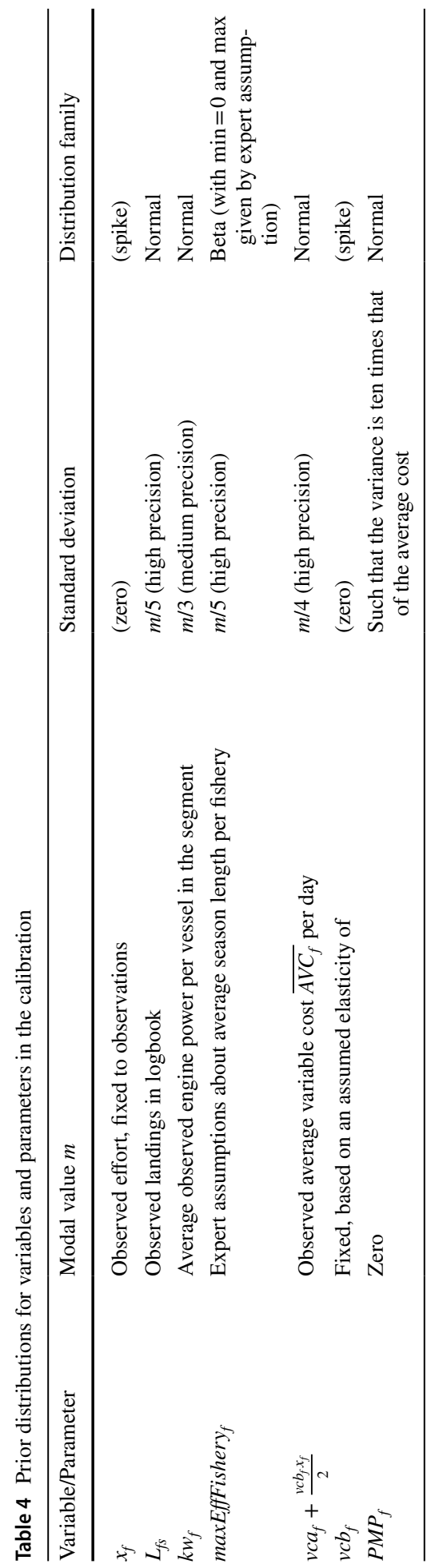




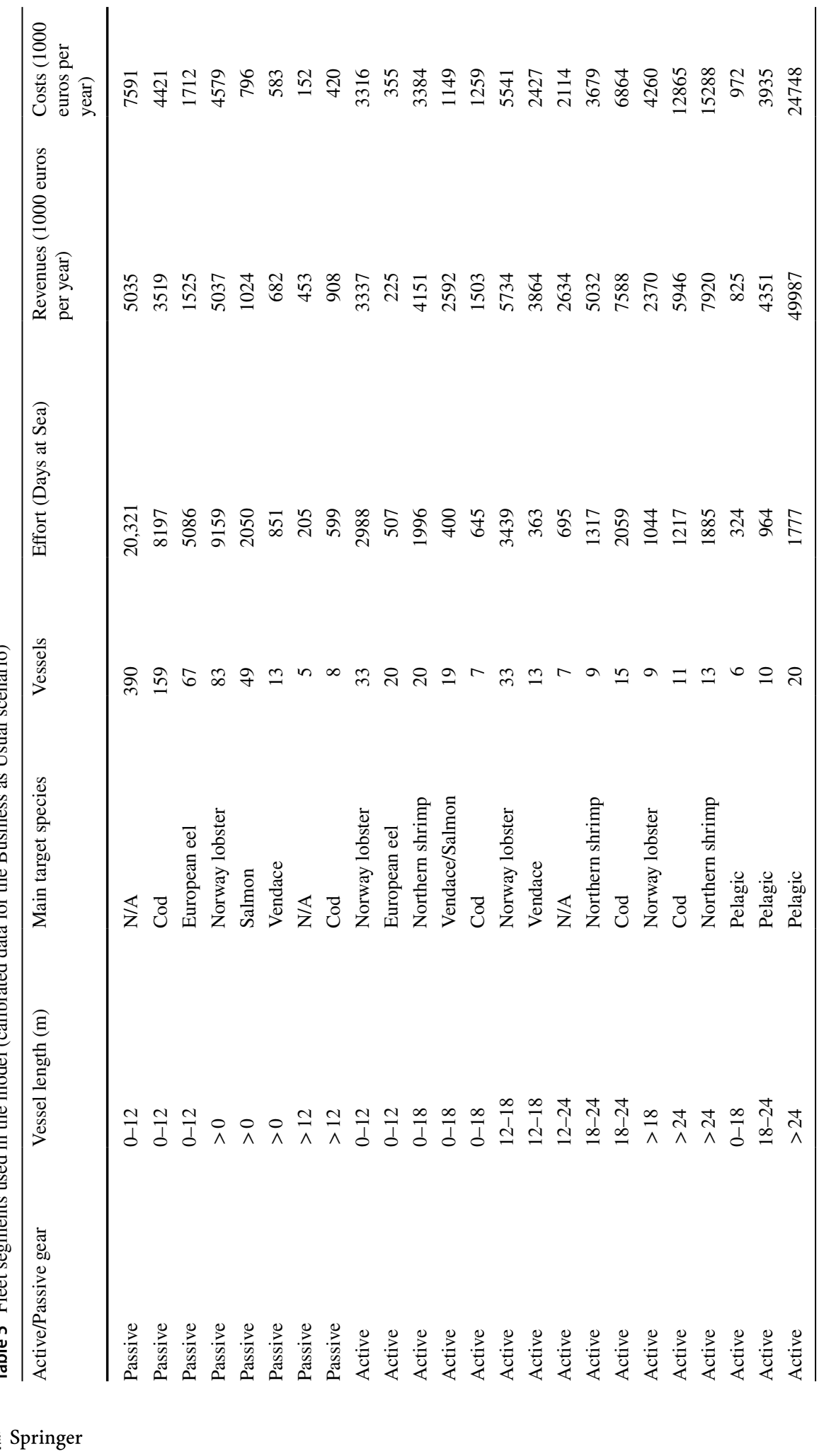


The final term penalty is defined as the sum of complementarity gaps multiplied by a weight $\frac{1}{\mu}$,

$\begin{gathered}\mu^{\prime} \\ \text { penalty }\end{gathered}=\frac{1}{\mu}\left(\sum_{q s, q a} \delta_{q s, q a}^{q u o t a}+\sum_{f} \delta_{f}^{\text {season }}+\sum_{\text {seg }} \delta_{\text {seg }}^{\text {maxEfSSeg }}+\sum_{\text {eg,ea }} \delta_{\text {eg,ea }}^{\text {maxEfReg }}\right)$. In the solution of the estimation problem, the weight of the penalty is initially set to something small and then increased stepwise until the complementarity gaps are zero and thus the CSC conditions are satisfied and we have an optimal solution to the primal fisheries model that maximizes the posterior density function. See (Tables 4 and 5).

Acknowledgements This work was supported by the Swedish Research Council for Sustainable Development (Formas) under grant no 942-2015-402. Further, we greatly acknowledge comments from two anonymous reviewers.

Funding Open access funding provided by Swedish University of Agricultural Sciences.

Open Access This article is licensed under a Creative Commons Attribution 4.0 International License, which permits use, sharing, adaptation, distribution and reproduction in any medium or format, as long as you give appropriate credit to the original author(s) and the source, provide a link to the Creative Commons licence, and indicate if changes were made. The images or other third party material in this article are included in the article's Creative Commons licence, unless indicated otherwise in a credit line to the material. If material is not included in the article's Creative Commons licence and your intended use is not permitted by statutory regulation or exceeds the permitted use, you will need to obtain permission directly from the copyright holder. To view a copy of this licence, visit http://creativecommons.org/licenses/by/4.0/.

\section{References}

Arata L, Donati M, Sckokai P, Arfini F (2017) Incorporating risk in a positive mathematical programming framework: a dual approach. Aust J Agric Res Econ 61(2):265-284. https://doi.org/10.1111/14678489.12199

Basnet K, Jansson T, Heckelei T (2021) A Bayesian econometric and risk programming approach for analysing the wealth effect of decoupled payments in Sweden. Aust J Agric Resour Econ 65:729

Bauer S, Kasnakoglu H (1990) Non-linear programming models for sector and policy analysis: experiences with the Turkish agricultural sector model. Econ Modell 7(3):275-29

Bergenius M, Ringdahl K, Sundelöf A, Carlshamre S, Wennhage H, Valentinsson D (2018) Atlas över svenskt kust- och havsfiske 2003-2015. Aqua reports 2018:3. Sveriges lantbruksuniversitet, Institutionen för akvatiska resurser, Drottningholm Lysekil Öregrund.

Bosetti V, Pearce DW (2003) A study of environmental conflict: the economic value of grey seals in Southwest England. Biodivers Conserv 13:2361-2392

Boncoeur J, Alban F, Guyader O, Thébaud O (2002) Fish, fishers, seals and tourists: economic consequences of creating a marine reserve in a multi-species multi-activity context. Nat Resour Model 15(4):387-411

Brinson A, Thunberg E (2016) Perfornmance of federally managed catch share fisheries in the United States. Fish Res 179:213-223

Buysse J, Van Huylenbroeck G, Lauwers L (2007) Normative, positive and econometric mathematical programming as tools for incorporation of multifunctionality in agricultural policy modelling. Agr Ecosyst Environ 120(1):70-81

Cook R, Trijoulet V (2016) The effects of grey seal predation and commercial fishing on the recovery of a depleted cod stock. Can J Fish Aquat Sci 73(9):1319-1329

Costalago D, Baue B, Tomczak M, Lundström K, Winder M (2019) The necessity of a holistic approach when managing marine mammal-fisheries interactions: environment and fisheries impact are stronger than seal predation. Ambio 48:552-564

Cronin M, Jessopp M, Houle J, Reid D (2014) Fishery-seal interactions in Irish waters: current perspectives and future research priorities. Mar Policy 44:120-130

Eero M, Hjelm J, Behrens J, Buchmann K, Cardinale M, Casini M, Gasyukov P, Holmgren N, Horbowy J, Hussy K, Kirkegaard E, Kornilovs G, Krumme UW, Köster F, Oeberst R, Plikshs M, Radtke K, Raid 
T, Schmid J, Tomczak M, Vinther M, Zimmermann C, Storr-Paulsen M (2015) Eastern baltic cod in distress: biological changes and challenges for stock assessment. ICES J Mar Sci 72(8):2180-2186

European Commission (2009) Council Regulation (EC) No. 1224/2009 of November 20, 2009. Establishing a Community Control System for Ensuring Compliance with the Rules of the Common Fisheries Policy, with Amendments. Official Journal of the European Union, Brussels, EC, 2009.

European Union (1992) The Council Directive 92/43/EEC on the Conservation of Natural Habitats and of Wild Fauna and Flora. Official Journal of the European Communities No. L 206/7.

European Union (2008a) Directive 2008/56/EC of the European Parliament and of the Council Establishing a Framework for Community Action in the Field of Marine Environmental Policy (Marine Strategy Framework Directive) Official Journal of the European Communities No. L 164/19.

European Union (2008b) Council Regulation (EC) No. 1342/2008 of December 18, 2008. Establishing a Long-Term Plan for Cod Stocks and the Fisheries Exploiting those Stocks and Repealing Regulation (EC) No 423/2004. Official Journal of the European Union 24.12.2008

European Union (2013) Common Fisheries Policy. Regulation (EU) No. 1380/2013 of the European Parliament and of the Council, December 11, 2013.

Facchinei F, Jiang H, Qi L (1999) A smoothing method for mathematical programs with equilibrium constraints. Math Program 85(1):107-134

Finnoff D, Tschirhart J (2003) Protecting an endangered species while harvesting its prey in a general equilibrium ecosystem model. Land Econ 79(2):160-180

Flaaten O, Stollery K (1996) The Economic Cost of biological predation: theory and application to the case of the Northeast Atlantic minke whale's (balaenoptera acutorostrata) consumption of fish. Environ Resour Econ 8:75-95

Frost H, Andersen P, Hoff A (2013) Management of complex fisheries: lessons learned from a simulation model. Can J Agric Econ 61:283-307

Greene WH (2003) Econometric analysis. Prentice Hall, New Jersey

Goldswothy S, Bailleul F, Nursey-Bray M, Mackay A, Oxley A, Reinhold S-L, Shaughnessy P (2019) Assessment of the impact of seal population on the seafood industry in South Australia. Assessment of the impacts of seals on the seafood industry in South Australia. Assessment of the impacts of seals on the seafood industry in South Australia.

Hansson S, Bergström U, Bonsdorff E, Härkönen T, Jepsen N, Kautsky L, Lundström K, Lunneryd SG, Ovegård M, Salmi J, Sendek D, Vetemaa M (2017) Competition for the fish-fish extraction from the baltic sea by humans, aquatic mammals and birds. ICES J Mar Sci 75(3):999-1008

Harding K, Härkönen T (1999) Development in the baltic grey seal (Halichoerus grypus) and Ringed Seal (Phoca hispida) populations during the 20th century. Ambio 28(7):619-627

Heckelei T (2002) Calibration and estimation of programming models for agricultural supply analysis. Rheinische Friedrich-Wilhelms-Universität Bonn, Habilitationsschrift

Heckelei T, Wolff H (2003) Estimation of constrained optimisation models for agricultural supply analysis based on generalised maximum entropy. Eur Rev Agric Econ 30(1):27-50

Heckelei T, Britz W, Zhang Y (2012) Positive mathematical programming approaches - RECENT developments in literature and applied modelling. Bio-Based Appl Econ 1(1):109-124. https://doi.org/10. 13128/BAE-10567

Helcom (2018) Distribution of Baltic Seals. Helcom Core Indicator Report of July 2018. Helcom Indicators.

Hemmingsson M, Fjälling A, Lunneryd SG (2008) The pontoon trap: description and function of a seal-safe trap-net. Fisheries Res 93:357359

Holma M, Lindroos M, Oinonen S (2014) The economics of conflicting interests: northern baltic salmon fishery adaption to gray seal abundance. Nat Resour Model 27(3):275-299

Howitt RE (1995) Positive mathematical programming. Am J Agr Econ 77(2):329-342

Jackman J, Bettencourt L, Vaske J, Sweeney M, Bloom K, Rutberg A, Brook B (2018) Conflict and consensus in stakeholder views of seal management on Nantucket Island, MA, USA. Mar Policy 95:166-173

Jansson T, Heckelei T (2009) A new estimator for trade costs and its small sample properties. Econ Model 26(2):489-498

Jansson T, Heckelei T (2010) Estimation of parameters of constrained optimization models. In: Gilbert $\mathbf{J}$ (ed) New developments in computable general equilibrium analysis for trade policy. Emerald Group Publishing, UK

Jansson T, Heckelei T (2011) Estimating a primal model of regional crop supply in the European Union. J Agric Econ 62(1):137-152

Johansson M, Waldo $\AA$ (2020) Local people's appraisal of the fishery-seal situation in traditional fishing villages on the Baltic Sea Coast in Southeast Sweden. Soc Nat Resour. https://doi.org/10.1080/ 08941920.2020 .1809756 
Jonasson L, Apland J (1997) Frontier technology and inefficiencies in programming sector models: An application to Swedish agriculture. Eur Rev Agric Econ 24(1):109-131. https://doi.org/10.1093/ erae/24.1.109

Königson S, Fjälling A, Lunneryd SG (2007) Grey seal induced catch losses in the herring gillnet fishery $n$ the Northern Baltic. NAMMCO Scientific Publ 6:203-213

Königson SJ, Fredriksson RE, Lunneryd SG, Strömberg P, Bergström UM (2015) Cod pots in a baltic fishery: are they efficient and what affects their efficiency? ICES J Mar Sci 72(5):1545-1554

Königson S, Lunneryd SG, Stridh H, Sundqvist F (2009) Grey seal predation in cod gillnet fisheries in the central Baltic Sea. J Northwest Atlantic Fisheries Sci 42:41-47

Lent R, Squires D (2017) Reducing marine mammal bycatch in global fisheries: an economics approach. Deep-Sea Res Part II 140:268-277

Magera A, Mills Flemming J, Kaschner K, Christensen L, Lotze H (2013) Recovery trends in marine mammal populations. PLoS ONE 8:10

Mérel P, Bucaram S (2010) Exact calibration of programming models of agricultural supply against exogenous supply elasticities. Eur Rev Agric Econ 37(3):395-418

Nielsen JR, Thunberg E, Holland D et al (2018) Integrated ecological-economic fisheries models - evaluation, review and challenges for implementation. Fish Fish 19:1-29

Nilssen K, Lindstrøm U, Westgaard J, Lindblom L, Blencke TR, Haug T (2019) Diet and prey consumption of grey seals (Halichoerus grypus) in Norway. Mar Biol Res 15(2):137-149. https://doi.org/10. 1080/17451000.2019.1605182

Nunny L, Simmonds M, Butterworth A (2018) A review of seal killing practice in Europe: implications for animal welfare. Mar Policy 98:121-132

Pollnac R, Seara T, Colburn L (2015) Aspects of fishery management, job satisfaction, and well-being among commercial fishermen in the Northeast Region of the United States. Soc Nat Resour 28:75-92

Prellezo R, Accadia P, Andersen JL, Andersen BS, Buisman E, Little A, Nielsen JR, Poos JJ, Powell J, Röckmann C (2012) A Review of EU bio-economic models for fisheries: the value of a diversity of models. Mar Policy 36:423-431

Read A (2008) The looming crisis: interactions between marine mammals and fisheries. J Mammal 89(3):541-548

Read A, Drinker P, Northridge S (2006) Bycatch of marine mammals in US and global fisheries. Conserv Biol 20(1):163-169

Reidy R (2019) Understanding the barriers to reconciling marine mammal-fishery conflicts: a case study in British Columbia. Mar Policy. https://doi.org/10.1016/j.marpol.2019.103635

Ryan C, Bolin V, Shirra L, Garrard P, Putsey J, Vines J, Hartny-Mills L (2018) The development and value of whale-watch tourism in the West of Scotland. Tour Mar Environ 13(1):17-24

Röhm O, Dabbert S (2003) Integrating Agri-Environmental Programs into Regional Production Models: An Extension of Positive Mathematical Programming. American Journal of Agricultural Economics 85(1):254-265 Available at: http://www.jstor.org/stable/1244941

Salz P, Buisman FC, Soma K, Frost H, Accadia P, Prellezo R (2011) FISHRENT; Bio-economic simulation and optimisation model. LEI report 2011-024. Available at: http://edepot.wur.nl/169748

SFS 2008:437. Förordning (2008:437) om statligt stöd av mindre betydelse inom jordbrukssektorn och sektorn för fiskeri och vattenbruk. Näringsdepartementet. In Swedish.

Shackelford G, Steward P, German R, Sait S, Benton T (2015) Conservation planning in agricultural landscapes: hotspots of conflict between agriculture and nature. Divers Distrib 21:357-367

Sokolova M, Buchmann K, Huwer B, Kania PW, Krumme U, Galatius A, Hemmer-Hansen J, Behrens JW (2018) Spatial patterns in infection of cod Gadus morhua with the seal-associated liver worm Contracaecum osculatum Sensu Stricto from the Skagerrak to the Central Baltic Sea. Mar Ecol Progr Ser 606:105-118

STECF (2018) The 2018 Annual Economic Report on the EU Fishing Fleet: Scientific, Technical and Economic Committee for Fisheries (STECF) Publications Office of the European Union, Luxembourg, 2018.

SwAM (2012) Nationell förvaltningsplan för gråsäl (Halichoerus grypus) i Östersjön. Havs- och vattenmyndigheten 2012-09-24. Gothenburg. In Swedish.

SwAM (2019) Reviderad nationell förvaltningsplan för gråsäl (Halichoerus grypus) i Östersjön. Havs- och vattenmyndighetens rapport 2019:24.Gothenburg. In Swedish.

SwAM (2014) Sälpopulationernas tillväxt och utbredning samt effekterna av sälskador i fisket. Redovisning av ett regeringsuppdrag. Swedish Agency for Marine and Water Management, report 2014-12-30. In Swedish.

SwAM and Swedish Board of Agriculture. 2021. Strategi för svenskt fiske och vattenbruk 2021-2026 friska ekosystem och hållbart nyttjande. Swedish Agency for Marine and Water Management and 
Swedish Board of Agriculture. Accessed 202108-26 at https://webbutiken.jordbruksverket.se/sv/artik lar/ovr598.html

Swedish EPA (2020) Beslut om licensjakt efter gråsäl 2020 och början av 2021. Swedish Environmental Protection Agency No NV-00236-20. 2020-04-06. In Swedish.

Sweeney JR, Howitt RE, Ling Chan H, Pan M, Leung P (2017) How do fishery policies Affect Hawaii's longline fishing industry? calibrating a positive mathematical programming model. Nat Res Model 30(2):941

Waldo S, Blomquist J (2020) Var är det lönt att fiska? - en analys av fisket i svenska regioner. AgriFood Fokus Rapport 2020:2

Waldo S, Paulrud A, Blomquist J (2020) The economic costs of seal presence in Swedish small-scale fisheries. ICES J Mar Sci 77(2):815-825

Waldo A, Johansson M, Blomquist J, Jansson T, Königson S, Lunneryd SG, Persson A, Waldo S (2020) Local attitudes towards management measures for the co-existence of seals and coastal fisheries - A Swedish case study. Marine Policy 118:104018

Wendt I, Carl C (1991) The statistical distribution of the mean squared weighted deviation. Chem Geol 9:275-285

Wickens P (1995) A Review of Operational Interactions between Pinnipeds and Fisheries. FAO Fisheries Technical Paper 346. Food and Agricultural Organization of the United Nations, Rome.

Wood SA, Frasier TR, McLeod BA, Gilbert JR, White BN, Bowen BD, Mammill MO, Waring GT, Brault S (2011) The genetics of recolonization: an analysis of the stock structure of grey seals (Halichoerus grypus) in the Northwest Atlantic. Can J Zool 89:490-497

Publisher's Note Springer Nature remains neutral with regard to jurisdictional claims in published maps and institutional affiliations. 